\title{
Technè
}

La science au service de l'histoire de l'art et de la préservation des biens culturels

$44 \mid 2016$

Archives de l'humanité : les restes humains patrimonialisés

\section{Préambule aux techniques d'analyses et de recherche}

Introduction to analytical and scientific research techniques

\section{Alain Froment}

\section{(2) OpenEdition}

12 Journals

\section{Édition électronique}

URL : http://journals.openedition.org/techne/1009

DOI : 10.4000/techne.1009

ISSN : 2534-5168

\section{Éditeur}

C2RMF

\section{Édition imprimée}

Date de publication : 1 novembre 2016

Pagination : $48-49$

ISBN : 978-2-7118-6339-6

ISSN : 1254-7867

Référence électronique

Alain Froment, "Préambule aux techniques d'analyses et de recherche », Technè [En ligne], 44 | 2016, mis en ligne le 19 décembre 2019, consulté le 25 septembre 2020. URL : http://

journals.openedition.org/techne/1009; DOI : https://doi.org/10.4000/techne.1009

\section{(c) (i) (9)}

La revue Technè. La science au service de l'histoire de l'art et de la préservation des biens culturels est mise à disposition selon les termes de la Licence Creative Commons Attribution - Pas d'Utilisation

Commerciale - Pas de Modification 4.0 International. 


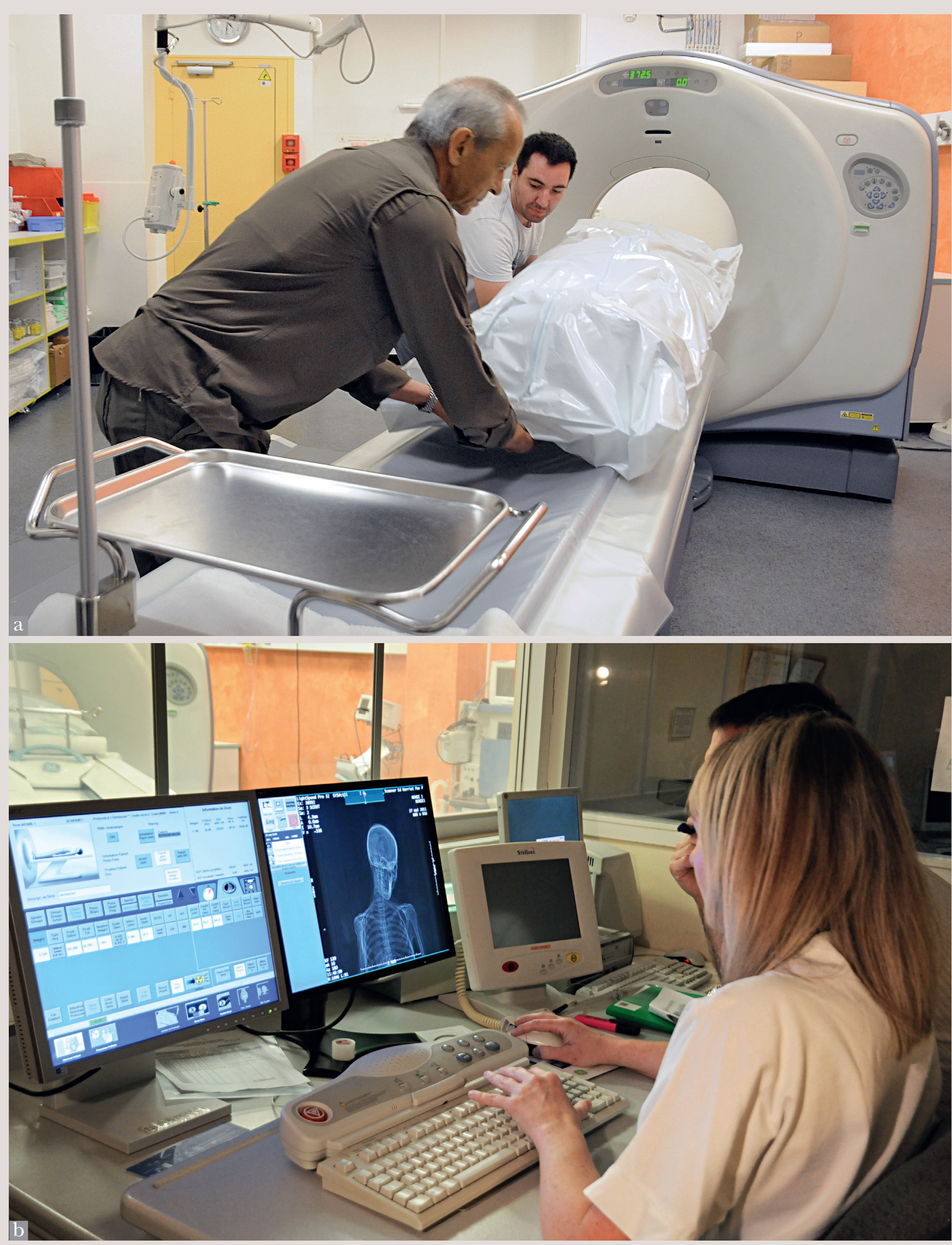

Fig. 1 a b. Scan de la « Momie 1 » du musée d'Anatomie Testut-Latarjet de Lyon, sur scanner de l'hôpital Édouard-Herriot, CHU de Lyon (remerciements Pr Olivier Rouvière).

(c) E. Le Roux/Communication/UCBL. 


\section{Alain Froment}

\section{Préambule aux techniques d'analyses et de recherche}

Introduction to analytical and scientific research techniques

de leur désintégration fournit un arsenal de datations (voir l'article de P. Richardin et M. Coudert dans ce numéro).

Par ailleurs, les marques d'activité musculaires s'impriment sur les insertions osseuses des muscles sollicités et permettent de reconstituer certaines pratiques, comme l'archerie, la cavalerie ou le dimorphisme sexuel des activités, conduisant à approcher ce que Leroi-Gourhan a appelé une paléontologie du geste. La traumatologie est aussi inscrite dans les os et révèle bien des comportements sociaux, de la guerre à la violence conjugale. Dans le cas particulier des momies, on peut mener des études sur les viscères (analyses diététiques, microbiologiques et parasitaires) et sur les pollens ou les insectes (voir l'article de J.-B. Huchet dans ce numéro) qui illustrent l'histoire du cadavre. Sur les cheveux comme sur les os, et sous certaines conditions taphonomiques, des polluants comme le plomb, l'arsenic ou quelques molécules organiques (voir l'article de J. Langlois et S. Pagès-Camagna dans ce numéro) éclairent les conditions environnementales dans lesquelles ont vécu ces individus.

On le voit, les collections de restes humains constituent donc de véritables archives, qui racontent soit l'histoire de la médecine et des maladies, lorsqu'il s'agit de pièces pathologiques, soit tout simplement l'histoire de nos ancêtres, de tous les ancêtres, de tous les peuples du monde.

Notes

1. Larsen, Walker, 2010

Référence bibliographique

Larsen C. S., Walker P. L., 2010, "Bioarchaeology: Health, Lifestyle, and Society in Recent Human Evolution" in A Companion to Biological Anthropology, Clark Spencer Larsen (ed), Blackwell Publ., p. 379-394. 